\title{
Temporal genetic homogeneity among shore crab (Carcinus maenas) larval events supplied to an estuarine system on the Portuguese northwest coast
}

\author{
CP Domingues ${ }^{1,2}$, S Creer ${ }^{2}$, MI Taylor ${ }^{2}, \mathrm{H}$ Queiroga ${ }^{1}$ and GR Carvalho ${ }^{2}$ \\ ${ }^{1}$ CESAM \& Departamento de Biologia, Universidade de Aveiro, Campus Universitário de Santiago, Aveiro, Portugal and ${ }^{2}$ Molecular \\ Ecology \& Fisheries Genetics Laboratory, School of Biological Sciences, Environment Centre Wales, Bangor University, Bangor, UK
}

\begin{abstract}
Despite the importance of larval biology in the life histories of many marine animals, relatively little information exists on the dynamics and genetic composition of larval cohorts. The supply of megalopae larvae of the shore crab, Carcinus maenas, was measured on a daily basis during 8 months spread along two larval periods (2006 and 2007) at the Ria de Aveiro estuary, on the Portuguese northwest coast. A total of 10 microsatellite DNA loci were employed to explore the genetic structure, variability and relatedness of temporally distinct megalopal events, selected from the major pulses of supply. Larval variation was also compared genetically with that of a previously studied adult crabs sample, at the same loci, collected in 2006 and 2007 along the Iberian Peninsula. Results revealed a lack of genetic differentiation and identical diversity levels among larval events over time. No evidence of
\end{abstract}

reduced genetic diversity between megalopae relative to the diversity assessed from the pooled sample of adults was found. Moreover, there was no evidence of any family relatedness among larvae from temporal events. The results obtained for C. maenas contradict predictions made by the sweepstakes reproduction hypothesis, in which large variance in reproductive success is expected, which is presumably detectable as sharp genetic discontinuities among separate larval events. Data here indicate conversely a high degree of temporal genetic stability among larval supply to a given estuary under variable oceanographic conditions, consistent with the hypothesis that sampled larvae were drawn from a large number of adults that do not differ in reproductive success.

Heredity (2011) 106, 832-840; doi:10.1038/hdy.2010.126; published online 20 October 2010

Keywords: reproductive success; relatedness; temporal genetic structure; larval dispersal; Carcinus maenas; microsatellite DNA

\section{Introduction}

The unpredictability of oceanographic conditions together with marine species' high fecundity and pronounced early life-stage mortality (type III survivorship curve) creates the potential for high variance in reproductive success among individuals, and is also referred to as sweepstakes reproduction (Hedgecock, 1994). According to the sweepstakes hypothesis, relatively few adults in each generation succeed in reproducing, as a result of stochastic processes leading to their reproductive activity coinciding with the correct oceanographic conditions conducive to spawning, fertilization, larval survival and recruitment (Hedgecock, 1994). Sweepstakes reproduction has been described in both invertebrates and fishes (Li and Hedgecock, 1998; Planes and Lenfant, 2002; Pujolar et al, 2006; Hedgecock et al., 2007b; Liu and Ely, 2009; Christie et al., 2010). Large discrepancies between the effective $\left(\mathrm{N}_{e}\right)$ and the census

Correspondence: $\operatorname{Dr} C P$ Domingues, CESAM \& Departamento de Biologia, Universidade de Aveiro, Campus Universitário de Santiago, Aveiro 3810-193, Portugal.

E-mail: cdomingues@ua.pt

Received 11 March 2010; revised 30 July 2010; accepted 2 September 2010; published online 20 October 2010
(N) population sizes usually resulting in very low $\mathrm{N}_{e} / \mathrm{N}$ ratios, are often reported among marine species (reviewed in Hauser and Carvalho, 2008) and are explained mainly by high variance in reproductive success. If this is the case, reduced genetic variability among cohorts of larvae or new recruits relative to the adult populations is expected (for example, Hedgecock et al., 2007b), as well as genetic differentiation among cohorts arriving at a population over time (for example, Li and Hedgecock, 1998). Moreover, larvae travelling in batches may be related by kin (Planes et al., 2002; Veliz et al., 2006), increasing the likelihood of differences among cohorts, though such relatedness may not always be evident (Hernbinger et al., 1997).

Several cases of temporal genetic heterogeneity among larval or recruit cohorts have been reported previously (Kordos and Burton, 1993; Ruzzante et al., 1996; Li and Hedgecock, 1998; Moberg and Burton, 2000; Planes and Lenfant, 2002; Pujolar et al., 2006; Selkoe et al., 2006; Liu and Ely, 2009), but such differences can be apportioned to variation in the adult reproductive contribution through random genetic drift within a single population only when immigration is ruled out ( $\mathrm{Li}$ and Hedgecock, 1998; Liu and Ely, 2009). For instance, temporal variation of megalopal allelic frequencies of the blue crab Callinectes sapidus in the Gulf of Mexico suggested 
changes in larval source populations throughout the recruitment season that were attributed to seasonal changes in coastal current patterns or to timing differences in spawning season (Kordos and Burton, 1993), rather than to transitory effects of variance in reproductive success. In other surveys (Ruzzante et al., 1996; Moberg and Burton, 2000; Planes and Lenfant, 2002; Pujolar et al., 2006; Selkoe et al., 2006), sweepstakes recruitment (Hedgecock, 1994) best explains the differentiation among cohorts but additional factors (for example, selection, spatial genetic variation, changes in larval delivery) could not be excluded. In contrast, some studies have found no reduced genetic diversity in recruits relative to estimates of diversity from adults (Flowers et al., 2002; Gilbert-Horvath et al., 2006; Rose et al., 2006; Calderón et al., 2009), no measurable genetic differentiation of recruits over time (Gilbert-Horvath et al., 2006; Calderón et al., 2009), no evidence of family structure (Hernbinger et al., 1997) and no reduction in effective population size (Poulsen et al., 2006) indicating little variance in reproductive success. It is evident therefore, that despite the prominence of stochastic larval supply events in the life histories of many marine animals no general trends can be derived from empirical observations. More studies analysing potential mechanisms driving differences among cohorts are needed and population structure analysis will benefit from the inclusion of a temporal genetic component and comparisons between the genetic composition of both adults and recruits.

In this study, we investigated the temporal genetic structure and tested the sweepstakes hypothesis in samples of megalopae larvae of the shore crab Carcinus maenas collected in the Ria de Aveiro estuary, on the Portuguese northwest coast. C. maenas is widely distributed along the European coast and whereas in northern Europe it inhabits a wider ecological niche occurring both in estuaries and in rocky shores, in southern Europe it is mostly restricted to estuarine habitats, such as Ria de Aveiro, where it forms large populations. C. maenas is a portunid crab with a life cycle that alternates between benthic adults that inhabit estuaries and rocky shores and planktonic larval stages that develop in shelf waters. The species is characterised by high fecundity, with females producing up to 200000 eggs per brood (Broekhuysen, 1936), from late winter to early summer, in northwest Portugal (Queiroga, 1995). Larvae are released as plankton to the open sea where they develop over 4 to 6 weeks, depending on temperature (Nagaraj, 1993). The larval series comprises four zoeae and terminates with one megalopa (Rice and Ingle, 1975), which is the stage that settles into benthic habitats before metamorphosis to the first crab stage. The supply of megalopae back to estuaries occurs mainly during highest amplitude tides around full and new moons, with peak abundance recorded from mid March to the end of July, and is enhanced by southerly winds or by northerly winds relaxation (Queiroga et al., 2006). Throughout larval development they are exposed to a combination of factors that affect their survival. Estimates of larval mortality in the field for decapod larvae are equivalent to an average instantaneous mortality rate of $7 \%$ per day (Rumrill, 1990).

High dispersal potential would contribute to maintain genetically homogeneous populations connected through larval dispersal along the Iberian Peninsula (Domingues et al., 2010). Despite this fact, it is reasonable to expect high variance in reproductive success, given that only a few individuals may successfully reproduce each year, genetic differences of which might be enough to cause genetic structure among larval events but not sufficient to impact adult population structure. In addition, the species' type III survivorship characteristics may result in the recruitment of genetically variable larval patches that can potentially contribute to transitory genetic differences among populations. These differences are illustrated by the divergence in the results observed by Pascoal et al. (2009) and Domingues et al. (2010), for the same geographical region. Finally, the oceanographic conditions along the western Iberian Peninsula ecosystem are variable throughout the year, and more unstable than previously thought (reviewed in Relvas et al., 2007). For example, during the winter months transient nearshore poleward flows, eddy shedding from the poleward slope current and even intermittent upwelling events are observed. After the spring transition, which is marked by a change on the general direction of the wind from poleward to equatorward, upwelling events increase in frequency, intensity and length and continue throughout the summer. Spatial and temporal heterogeneity in oceanographic conditions affect larvae during development and promote episodic and variable supply back to adult populations (Almeida and Queiroga, 2003; Queiroga et al., 2006), thereby influencing which larvae actually recruit to the next generation. The current understanding of the oceanographic mechanisms coupled with larval behaviour shows that diel vertical migration (dos Santos et al., 2008) promotes retention of crab larvae in the inner shelf during spring and early summer, through interaction with the two-layered flow typical of upwelling circulation (Marta-Almeida et al., 2006). Relaxation of upwelling causes translocation of the larvae to the near-shore environment; supply into estuaries then occurs by selective tidal stream transport (for example, Queiroga et al., 2006). Available laboratory and field studies indicate that pulses of decapod larvae of the same age react coherently to environmental stimuli (Queiroga and Blanton, 2005). This supports the view that larvae resulting from the same hatching event are subjected to essentially the same advection history. Indeed, individual patches of larvae may maintain their integrity throughout larval development (Natunewicz and Epifanio, 2001), allowing aggregations of larvae from the same family group to settle in close proximity. This process is supported by oceanographic predictions along the California Upwelling System (Siegel et al., 2008) and might also occur in a similar oceanographic system, along the Portuguese west coast.

Here, we analyse the genetic structure, variability and genetic relatedness of temporally separated $C$. maenas megalopal events from different supply episodes and to examine if these larval events are genetically differentiated and have reduced genetic diversity when compared with the putative spawning populations. In this way, we hope to elucidate whether relatedness within larval events or large variance in reproductive success is a common feature in the shore crab. These hypotheses were investigated using 10 microsatellite markers that were amplified in megalopae selected from eight major 
pulses of larval supply episodes that took place in the Ria de Aveiro estuary, Portugal, during two consecutive larval periods (2006 and 2007).

\section{Materials and methods}

\section{Sample collection}

Megalopae were collected from March to June from supply events that occurred in the 2006 and 2007 larval periods in Ria de Aveiro, a shallow coastal lagoon on north-western Portugal $\left(40^{\circ} 37^{\prime} 17^{\prime} \mathrm{N}, 8^{\circ} 44^{\prime} 56^{\prime} \mathrm{W}\right.$; Figure 1). Megalopae were collected with the use of two passive plankton nets described by Queiroga et al. (2006). The nets were deployed at a station inside the Ria de Aveiro facing the inlet, one below the surface and one above the bottom, within one tidal excursion from the inlet. The nets measured the absolute supply of megalopae to the Ria de Aveiro during flood. Every day, live megalopae were removed from the plankton samples and preserved in $96 \%$ ethanol for DNA extraction. A total of 2800 and 1106 megalopae were collected in 2006
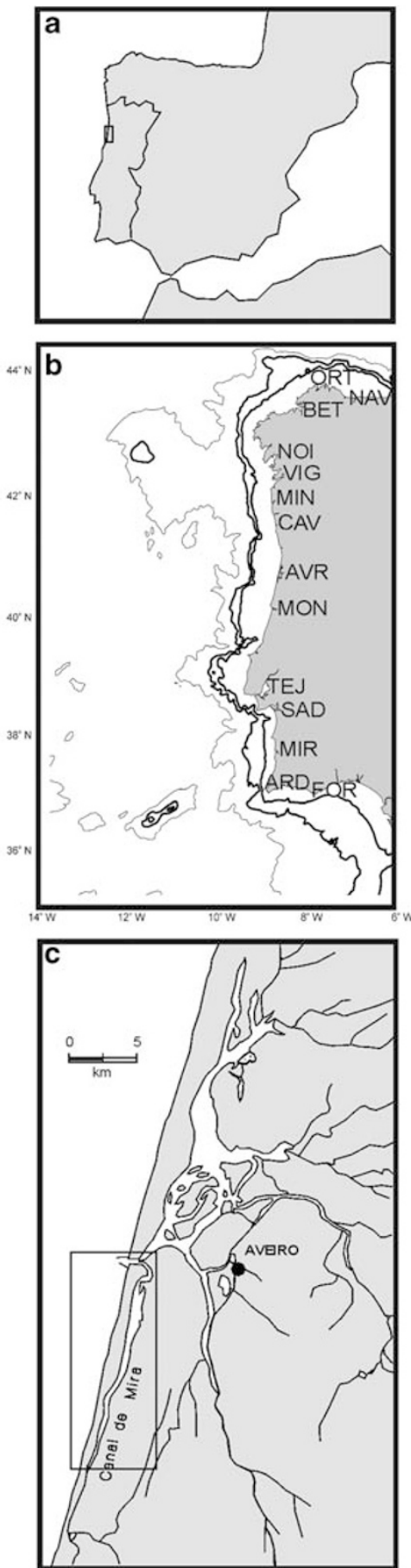

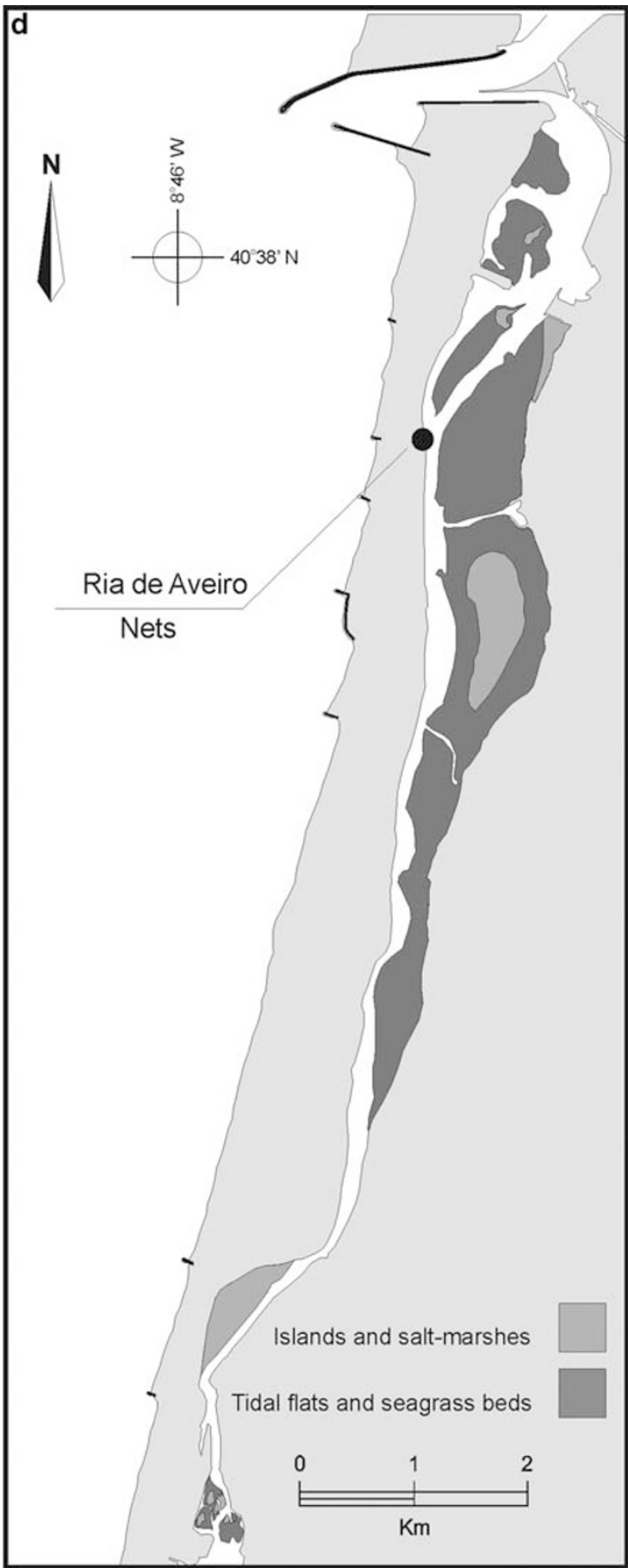

Figure 1 Sampling location for Carcinus maenas megalopae and adult crabs collection. (a) Iberian Peninsula, (b) Sampling location for adult crabs, AVR: Ria de Aveiro (for details see Domingues et al., 2010) (c) Ria de Aveiro, NW Portugal and (d) Sampling location for megalopae. 

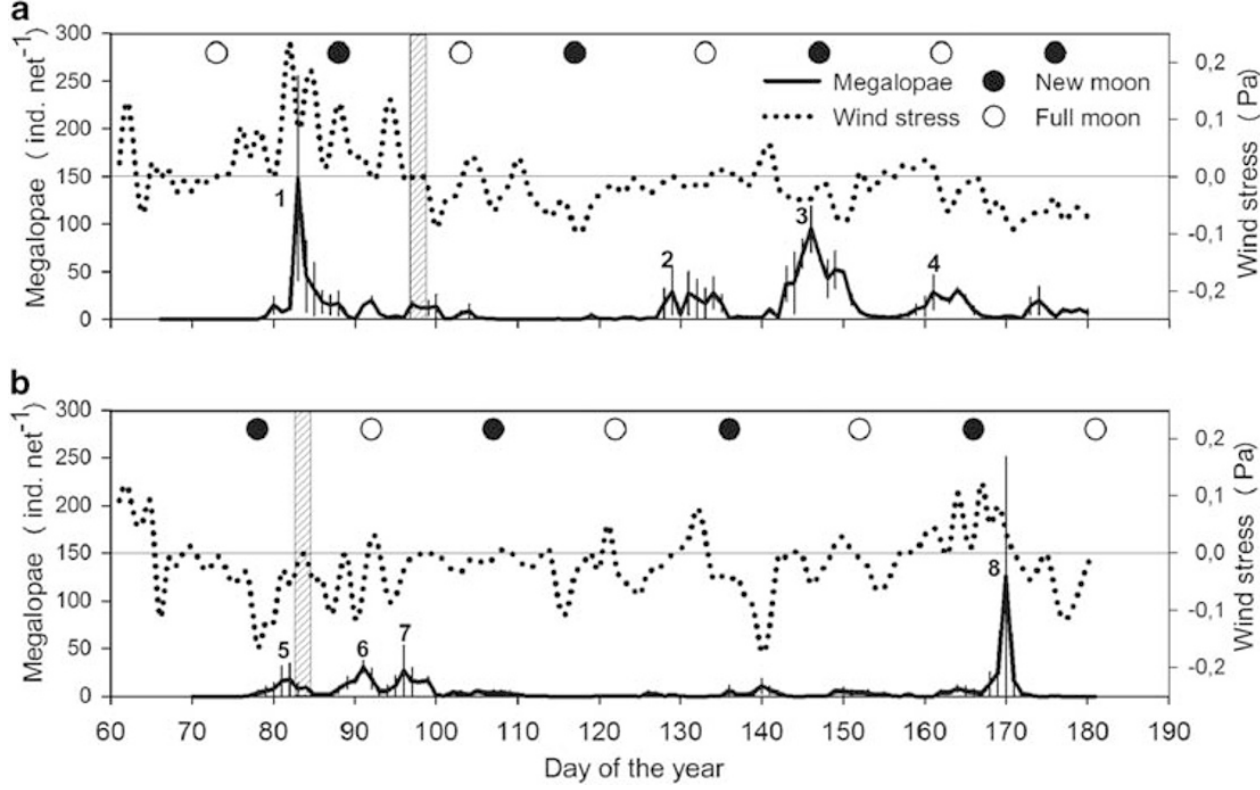

Figure 2 Average daily numbers of megalopal supply and along-shore wind stress values, in Ria de Aveiro. (a) 2006 and (b) 2007. As the Portuguese west coast has an approximate north-south orientation and according to the upwelling theory we computed the along-shore component of wind stress (for details see Queiroga et al., 2006). Wind stress with a negative component indicates northerly winds, which favour upwelling; wind stress with a positive component indicates southerly winds, which favour downwelling. Numbers identify supply events from where megalopae were selected for genetic analysis. Shaded bars indicate the spring transition according to the intensity and magnitude of along-shore winds. Error bars: \pm 1 s.e.

Table 1 Identification of samples including larval supply events, adult population, collection periods and sample sizes

\begin{tabular}{lccc}
\hline Larval event & Supply event & Collection period & Sample size \\
\hline E06.1 & 1 & 24 March 2006 & 98 \\
E06.2 & 2 & 11-12 May 2006 & 94 \\
E06.3 & 3 & 26 May 2006 & 100 \\
E06.4 & 4 & 12-13 June 2006 & 91 \\
E07.5 & 5 & 22-25 March 2007 & 75 \\
E07.6 & 6 & 6-7 April 2007 & 75 \\
E07.7 & 7 & 19-22 May 2007 & 37 \\
E07.8 & 8 & 19 June 2007 & 82 \\
Adult population & & Summer 2006 \& 2007 & 1262 \\
IP & & & \\
\hline
\end{tabular}

Abbreviation: IP, iberian Peninsula.

Each larval event is made up of a group of megalopae collected from each larval supply event according to Figure 2.

and 2007, respectively, across eight main discrete megalopal supply events (Figure 2). Each event lasted 3 to 5 days and, whenever possible, 80-100 megalopae per event were randomly selected, proportionally to abundance in the surface and bottom nets, from the day of maximum supply, or from proximate days in events with a low number of larvae (Table 1). Genetic variation of megalopae was compared with 1262 previously analysed adult crabs collected from 14 estuaries along a $1200 \mathrm{~km}$ stretch of the Iberian Peninsula in the summer of 2006 and 2007 (Domingues et al., 2010), pooled in a single sample, referred to as 'Iberian Peninsula' adult population (Table 1).

\section{DNA extraction and microsatellite genotyping}

Before DNA extraction, megalopae were placed in distilled water to rehydrate larvae and wash possible contaminants attached to the animals. Total genomic
DNA was extracted from whole megalopa using overnight digestion with Proteinase $\mathrm{K}$ following a modified salt extraction protocol (Aljanabi and Martinez, 1997). DNA was resuspended in a volume of $100 \mu \mathrm{l}$ of $1 \times \mathrm{TE}$ buffer (10 mM Tris-Cl, $1 \mathrm{mM}$ EDTA, $\mathrm{pH} 8.0)$ and stored at $-20^{\circ} \mathrm{C}$. The samples were genotyped using the same ten species-specific microsatellite loci selected by Domingues et al. (2010) (Supplementary Table 1), to allow comparisons with results from adult population: Cma01EPA, Cma03EPA, Cma04EPA, Cma05EPA, Cma08EPA, Cma09EPA, Cma10EPA, Cma14EPA (Tepolt et al., 2006), SP107 and SP495 (Pascoal et al., 2009). Microsatellite loci were amplified in two multiplex PCR performed in $10 \mu \mathrm{l}$ reactions containing $1 \mu \mathrm{l}$ of the template DNA, $1 \times$ QIAGEN Multiplex PCR Master Mix (Qiagen, Crawley, West Sussex, UK) and 0.1-0.3 $\mu \mathrm{M}$ of each primer (forward 6-FAM, VIC, NED or PET fluorescently labelled primers). Reactions were carried out in Bio-Rad (Hemel Hempstead, Hertfordshire, UK) Tetrad2 Peltier Thermal Cyclers under the following conditions: $95^{\circ} \mathrm{C}$ for $15 \mathrm{~min}$ followed by 30 cycles of $94{ }^{\circ} \mathrm{C}$ for $30 \mathrm{~s}, 55^{\circ} \mathrm{C}$ for $90 \mathrm{~s}$ and $72{ }^{\circ} \mathrm{C}$ for $60 \mathrm{~s}$ followed by a final extension at $60^{\circ} \mathrm{C}$ for $30 \mathrm{~min}$. Fragments were separated on a ABI $3130 \times 1$ Genetic Analyzer (Applied Biosystems, Foster City, CA, USA) and alleles were scored relative to the internal size standard GeneScan LIZ-500 using GENEMAPPER version 4.0 (Applied Biosystems).

\section{Genetic analysis}

Scoring reliability was ensured by running MICROCHECKER version 2.2.3 (van Oosterhout et al., 2004) to test for null alleles, stuttering or large allele drop-out. FSTAT version 2.9.3.2 (Goudet, 2001) was employed for calculating Wright's $F_{I S}$ and $F_{S T}$ (Weir and Cockerham, 1984), number of alleles $\left(\mathrm{N}_{\mathrm{A}}\right)$, allelic richness $(\mathrm{A})$ and for 
testing Hardy-Weinberg proportions using $F_{I S}$, after 10000 randomizations. Genetic differences among larval events were tested using global Fisher's exact tests based on allelic (genic) and genotype (genotypic) frequencies performed in GENEPOP version 4.0 (Rousset, 2008), with significance levels estimated using the Markov chain method. GENETIX version 4.05 (Belkhir et al., 1996-2004) was used for calculating expected $\left(\mathrm{H}_{\mathrm{E}}\right)$ and observed $\left(\mathrm{H}_{\mathrm{o}}\right)$ heterozygosity and for comparing pairwise genetic differences $\left(F_{S T}\right)$ among larval events and among larval events and the adult population, with significances tested using 10000 permutations. Linkage equilibrium between pairs of loci was tested using the Markov chain exact probabilities obtained from GENEPOP version 4.0 (Rousset, 2008). Sequential-Bonferroni corrections were applied to account for multiple comparisons (Rice, 1989). The simulation procedure of Ryman et al. (2006) implemented in the software POWSIM version 4.0 (Ryman and Palm, 2006) was used to assess the alpha error and statistical power of our microsatellite loci to detect various true levels of divergence $\left(F_{S T}=0.0001\right.$, 0.0010 and 0.0100) among larval events, employing sample sizes corresponding to those from our events and the allele frequencies from the current data set. Each simulation was run 1000 times and power was determined as the proportion of simulations that Fisher's exact test detected significant at the 0.05 level. Differences in genetic diversity (in terms of expected heterozygosity and allelic richness) between larval samples and relative to the adult population were tested with Friedman analysis of variance (ANOVA) in STATISTICA version 8.0 StatSoft, Inc. (Tulsa, OK, USA). A hierarchical analysis of molecular variance (AMOVA) (Excoffier et al., 1992) was performed in GenAlex version 6.2 (Peakall and Smouse, 2006), computed on the proportion of variation among larval events, the proportion of variation among larvae within events and the proportion of variation within larvae, and tested for significance with 9999 permutations. We then performed a second AMOVA but grouped larval events according to the sampling year (2006 and 2007). Finally, in order to assess the potential seasonal effect of wind-driven circulation on larval genetic variation we performed two more AMOVAs, separately for each year, but pooling larvae collected before (less upwelling favourable) and after (upwelling favourable) the spring transition, which was measured by the intensity and frequency of along-shore winds (Figure 2). Estimates of average relatedness of all individuals to each other, across samples, were assessed using Queller and Goodnight (1989) statistic $r_{\mathrm{xy}}$ obtained using the program IDENTIX version 1.1 (Belkhir et al., 2002). The mean and the variance of $r_{x y}$ were estimated for each larval event, year and season and compared with their expected distribution, generated by 1000 permutation of alleles among individuals, under the null hypothesis of no relatedness (full-sibs, $r=0.50$; halfsibs, $r=0.25$; unrelated individuals, $r=0.00$ ).

\section{Results}

Genetic diversity within and between larval events and adult sample

Standard genetic estimates for each larval event and adult population are summarised in Table 2 .
Table 2 Summary statistics for each larval event and adult population of Carcinus maenas.

\begin{tabular}{lrrcccr}
\hline Larval event & \multicolumn{1}{c}{$\mathrm{N}$} & \multicolumn{1}{c}{$N_{\mathrm{A}}$} & $A$ & $H_{\mathrm{O}}$ & $H_{\mathrm{E}}$ & \multicolumn{1}{c}{$F_{I S}$} \\
\hline E06.1 & 98 & 13.3 & 9.691 & 0.679 & 0.680 & 0.002 \\
E06.2 & 94 & 12.2 & 9.280 & 0.681 & 0.689 & 0.012 \\
E06.3 & 100 & 13.1 & 9.510 & 0.691 & 0.692 & 0.001 \\
E06.4 & 91 & 13.5 & 9.707 & 0.689 & 0.684 & -0.007 \\
E07.5 & 75 & 12.6 & 9.561 & 0.673 & 0.676 & 0.004 \\
E07.6 & 75 & 12.4 & 9.482 & 0.658 & 0.682 & $0.034^{*}$ \\
E07.7 & 37 & 9.9 & 9.202 & 0.675 & 0.676 & 0.001 \\
E07.8 & 82 & 12.6 & 9.583 & 0.688 & 0.685 & -0.004 \\
Overall & 652 & 12.5 & 9.502 & 0.679 & 0.683 & 0.005 \\
Adult population & 1262 & 19.2 & 9.626 & 0.675 & 0.686 & $\mathbf{0 . 0 1 6}$ \\
IP & & & & & & \\
\hline
\end{tabular}

Abbreviations: A, allelic richness; $F_{I S}$, inbreeding coefficients, calculated after Weir and Cockerham (1984); $H_{\mathrm{E}}$, expected heterozygosity; $H_{\mathrm{O}}$, observed heterozygosity; $N$, sample size; $N_{\mathrm{A}}$, average number of alleles. Larval events were collected in Ria de Aveiro according to Figure 2 and adult population from pooled samples collected along the Iberian Peninsula. Asterisks indicate $P<0.05$ before correction for multiple tests. Bold indicate values that remain significant following Bonferroni correction.

Microsatellite allele frequencies for all samples by locus are listed in Supplementary Table 2. In total, 652 megalopae were analysed at 10 microsatellite loci. Of the 198 alleles recovered in both adult and larval samples, 24 were exclusively from the adult population and 5 were only present in the larval sample. MICROCHECKER found no evidence of scoring errors or null alleles in any sample. No departure from Hardy-Weinberg expectation after correcting for multiple tests (Rice, 1989) was detected in any of the eight larval events as well when we pooled samples from all events. In the adult population, a significant deficiency in heterozygosity was observed (Table 2). No evidence of linkage disequilibrium was found after sequential Bonferroni correction (Rice, 1989) among any of the loci within samples.

All larval samples exhibited comparable genetic diversity (Table 2) as no significant differences were found between temporally distinct larval events in expected heterozygosity (Friedman ANOVA, $\chi^{2}=2.57$, d.f. $=7, P=0.922$ ) and allelic richness (Friedman ANOVA, $\chi^{2}=6.33$, d.f. $=7, P=0.502$ ). Moreover, we found no evidence of reduced genetic diversity between larval events and the adult spawning population, assessed with expected heterozygosity (Friedman ANOVA, $\chi^{2}=3.01$, d.f. $=8, P=0.934$ ) and allelic richness (Friedman ANOVA, $\chi^{2}=6.89$, d.f. $=8, P=0.548$ ) (Table 2).

\section{Genetic structure within and between larval events and adult sample}

Overall genetic differentiation among larval events was very low (global $F_{S T}=0.0003$ ) and not statistically significant according to Fisher's exact test on both allelic $(P=0.164)$ and genotypic $(P=0.302)$ frequencies. Similarly, none of the pairwise $F_{S T}$ comparisons among larval events showed significant differences after sequential Bonferroni correction (Table 3). AMOVA, computed when considering all samples separately, revealed no significant variance among larval events $(0.16 \%$, $P=0.268)$. Similarly, only a small proportion of variation $(0.22 \%)$ was associated with differentiation according to 
Table 3 Measures of genetic differentiation based on $F_{S T}$ analysis

\begin{tabular}{|c|c|c|c|c|c|c|c|c|c|}
\hline & E06.1 & E06.2 & E06.3 & E06.4 & E07.5 & E07.6 & E07.7 & E07.8 & $I P$ \\
\hline E06.1 & & 0.4120 & 0.7794 & 0.5714 & 0.6675 & 0.3140 & 0.3262 & 0.4445 & 0.7221 \\
\hline E06.2 & 0.0001 & & 0.8533 & 0.1940 & 0.4610 & $0.0070^{*}$ & 0.7286 & 0.9326 & 0.4353 \\
\hline E06.3 & -0.0009 & & & 0.6948 & 0.5149 & 0.1303 & 0.2259 & 0.8901 & 0.5630 \\
\hline E06.4 & -0.0003 & 0.0010 & -0.0007 & & 0.7560 & 0.1181 & $0.0074^{*}$ & 0.4642 & 0.1281 \\
\hline E07.5 & -0.0007 & 0.0000 & -0.0002 & -0.0010 & & 0.1079 & 0.2208 & 0.5739 & 0.3168 \\
\hline E07.6 & 0.0005 & $0.0042^{*}$ & 0.0015 & 0.0016 & 0.0020 & & 0.0936 & 0.0684 & 0.0584 \\
\hline E07.7 & 0.0007 & -0.0014 & 0.0014 & $0.0063^{*}$ & 0.0017 & 0.0033 & & 0.7930 & 0.3882 \\
\hline E07.8 & 0.0000 & -0.0017 & -0.0014 & 0.0000 & -0.0004 & 0.0023 & -0.0018 & & 0.8482 \\
\hline IP & -0.0005 & 0.0000 & -0.0002 & 0.0007 & 0.0003 & 0.0014 & 0.0003 & -0.0007 & \\
\hline
\end{tabular}

Below diagonal, pairwise $F_{S T}(\theta)$ estimates of genetic differentiation between all samples (larval events and adult population). Above diagonal, $P$-values of the tests of genetic differentiation. Asterisks indicate $P<0.05$ before correction for multiple tests. None of the values remain significant following sequential Bonferroni correction.

Table 4 Estimates of average relatedness $\left(r_{x y}\right)$ from IDENTIX based on 10 microsatellite loci

\begin{tabular}{lc}
\hline Sample & $r_{x y}$ \\
\hline E06.1 & $-0.0107(0.0011)$ \\
E06.2 & $-0.0105(0.0011)$ \\
E06.3 & $-0.0105(0.0009)$ \\
E06.4 & $-0.0110(0.0010)$ \\
E07.5 & $-0.0145(0.0015)$ \\
E07.6 & $-0.0141(0.0016)$ \\
E07.7 & $-0.0246(0.0022)$ \\
E07.8 & $-0.0116(0.0014)$ \\
2006 & $-0.0027(0.0005)$ \\
2007 & $-0.0030(0.0008)$ \\
2006 AST & $-0.0035(0.0006)$ \\
2007 AST & $-0.0041(0.0009)$ \\
\hline
\end{tabular}

Standard deviations are in parenthesis. None of the values were significant after 1000 permutations. E06.1 and E07.5 correspond to the samples taken before the spring transition in 2006 and 2007, respectively. 2006 AST: samples pooled after the spring transition in 2006 (E06.2, E06.3 and E06.4); 2007 AST: samples pooled after the spring transition in 2007 (E07.6, E07.7 and E07.8).

the sampling year (2006 and 2007), which was not significant $(P=0.400)$. No significant differentiation was attributable to differences among larvae within larval events $(0.40 \%, P=0.260)$ or within larvae $(99.44 \%$, $P=0.246$ ). AMOVA of larval events pooled according to season revealed no significant differentiation between samples for both $2006(0.00 \%, P=0.568)$ and $2007(0.14 \%$, $P=0.180$ ) years.

Concerning differentiation between the adult population, Iberian Peninsula, and the larval events, pairwise $F_{S T}$ values revealed no significant genetic differentiation (Table 3).

The results of power analysis in POWSIM were estimated as $0.100\left(F_{S T}=0.0001\right), 0.948 \quad\left(F_{S T}=0.0010\right)$ and $1.000 \quad\left(F_{S T}=0.0100\right)$. Therefore, the simulations indicate that the number of individuals and the numbers of loci used in this study provide strong support to identify genetic structure at very low levels of true divergence in the range of $0.0001-0.0100$. The alpha error (the probability of obtaining significant genetic structure when the true $F_{S T}=0$ ) were consistently about $5 \%$ in all simulations.

Genetic relatedness within and between larval events Average relatedness was concordant and close to zero over all individuals within each larval event (ranged from -0.0246 to -0.0105$)$. Within years and seasons the values of genetic relatedness were also low (Table 4). Analysis of significance based on a permutation resampling test did not allow rejection of the null hypothesis of no relatedness within samples.

\section{Discussion}

The processes that regulate larval dispersal, recruitment and genetic variation within marine populations through time are not completely understood. Elucidation of processes requires the analysis of both spatial and temporal genetic variation of larvae or recruits and adult populations (Selkoe et al., 2008). Microsatellite DNA is a powerful genetic tool to detect differentiation and provenance of individuals recruiting to a given population (Selkoe and Toonen, 2006), even in species exhibiting high dispersal capacity, as in the shore crab C. maenas. An intensive sampling, over two years, of $14 \mathrm{C}$. maenas populations distributed along southern, western and northern Iberian Peninsula found genetically homogeneous populations (Domingues et al., 2010), and it is thus not possible to assign larvae recruiting to a particular estuary to putative source populations. We would expect a reduction of genetic diversity within larvae arriving at a given location relative to the adult source populations if only a small proportion of adult crabs contribute to reproduction at each spawning event. We would also expect genetic differences between temporally distinct larval supply episodes given that the mechanisms of larval dispersal and recruitment over time are strongly dependent on the interactions between larvae and variable aspects of wind-, tidal- and density-driven circulations (Queiroga and Blanton, 2005). For example, Hedgecock et al. (2007b) reported genetic divergence at four microsatellite loci between recruited juveniles and adults of the European flat oyster Ostrea edulis from western Mediterranean despite the genetic homogeneity observed among the adult populations. Interestingly, Planes et al. (2002) found significant allozyme variation between the larvae of the reef fish Naso unicornis relative to the juveniles and the adults, whereas juveniles and adults were similar. More recently, an exhaustive study of Selkoe et al. (2006) reported significant genetic differentiation at seven microsatellite loci among cohorts of settlers of the kelp bass Paralabrax clathratus. This differentiation was explained by family structure and by differences in larval distribution due to shifts in marine currents. In contrast, our results did not show reduced 
genetic variability among $C$. maenas megalopal events relative to the spawning population and also failed to show any significant temporal and seasonal (upwelling related) trend in genetic variability and in allele and genotype frequencies among distinct larval supply events, what is supported by the reasonable statistical power of our microsatellites to detect genetic structure. Average genetic relatedness analysis showed that each larval event is composed of a large group of unrelated megalopae and the same is true when we pooled larval events before and after the spring transition. Moreover, no departure from Hardy-Weinberg expectations was observed within or across all events. A slight deficit in heterozygotes was observed in the adult sample. This could be because of a Wahlund effect caused by small fluctuations in allele frequencies when pooling temporal samples, as well as heterogeneity resulting from temporary slight genetic differences among $C$. maenas populations along the Portuguese coast (Pascoal et al., 2009; Domingues et al., 2010).

The use of multiple approaches and the inclusion of oceanographic and behavioural information into genetic analysis will lead to a better understanding of the mechanisms regulating gene flow and connectivity among marine populations (reviewed in Selkoe et al., 2008). Data here were obtained under diverse oceanographic conditions such as: northerly winds favouring upwelling, as well as northerly winds relaxation and southerly winds favouring downwelling, which enhanced onshore supply of megalopae (Figure 2). The acquisition of daily data on larval supply during the entire larval period simultaneously with the acquisition of detailed information on physical variables allowed us to identify the discrete larval pulses and to select megalopae from the relevant episodes. At the same time, we conducted a detailed sampling of adult crab populations, comprising a distance of approximately $600 \mathrm{~km}$ to the south and to the north of Ria de Aveiro (Domingues et al., 2010). In this way, we maximised representative sampling of all putative spawning populations contributing to Ria de Aveiro populations (Peliz et al., 2007). The results presented in this study indicate no evidence of marked variance in reproductive success in C. maenas, at least using our markers and across the temporal and spatial scales examined. Nevertheless, we have noticed a recent decline in the supply of megalopae to Ria de Aveiro (for the same sampling period, with passive plankton nets: 2800 megalopae in 2006; 1106 megalopae in 2007; 1078 megalopae in 2008; 756 megalopae in 2009, unpublished data). The observed decline may result from variation in the output of larvae produced by the local populations, from fluctuations in phytoplankton production or from variation in transport processes along the coast. Ultimately a reduced larval supply may contribute to the reduction of $C$. maenas abundance in Ria de Aveiro, where the species undertakes an important ecological and socio-economic role, despite being an ecologically problematic species in non-native locations (Carlton and Cohen, 2003). High mortality is definitely occurring in early C. maenas life stages. Indirect estimates from data on abundance of zoea- 1 and the megalopa larvae in the Ria de Aveiro indicates a total mortality rate exceeding $90 \%$ during the larval phase (Queiroga et al., 1994). A lack of temporal genetic differences among samples was reinforced by data indicating a lack of significant genetic relatedness within larval events, suggesting that larvae were indeed drawn from a large number of adults. As a consequence, local populations are not constrained by the genetic makeup of the larval pool that must subsequently recruit in order to maintain large populations. Evidence shows that larval aggregations or 'parcels' (Siegel et al., 2008) may be retained in shelf waters after emission from estuaries (for example, Natunewicz and Epifanio, 2001; MartaAlmeida et al., 2006) and remain cohesive until settlement, making possible the detection of family structure within parcels if they were produced in the same spawning event. However, the longevity of such parcels may well depend locally on environmental heterogeneity, such as turbulence or small scale features of circulation that will disrupt the aggregations and mix larvae from different origins.

On the other hand, early post-settlement processes may have a significant role in the regulation of local populations (Hunt and Scheibling, 1997). Young juveniles experience high mortalities, especially due to predation, and as such represent a critical phase in the life-history of the shore crab (Moksnes et al., 1998). Studies examining the genetic composition of young recruits are then necessary to provide information about the contribution of the various life stages on population structure of $C$. maenas. Loci under selection can display high levels of genetic differentiation among populations showing evidence of adaptation to local environmental conditions that would not be uncovered by neutral microsatellite markers. As juvenile crab fitness may be under genetic control caused by intense selection in the field, the use of genetic markers under selection, for example, gene associated single-nucleotide polymorphisms, could also be useful for determining whether pre or post-settlement selection is taking place among different spatial and temporal scales (Hauser and Carvalho, 2008).

Contrary to what could be expected by the sweepstakes hypothesis we found no genetic differences and no relatedness among $C$. maenas larvae, as well as no reduced genetic diversity in larvae, when compared with adults along the western Iberian coast. This suggests that the phenomenon might not be as widespread among marine species as previously acknowledged (Hedgecock et al., 2007a). High temporal genetic homogeneity and stability of both larvae and adults suggest great connectivity among populations, which may explain the invasive success of the species around the globe. The lack of variance in reproductive success may indicate that the species has evolved to cope with a large variability of environmental conditions leading to high fitness across a large range of habitats. It is thus of relevant importance to continue surveying shore crab population using multiple approaches and integrating demographic, genetic, behavioural and oceanographic data.

\section{Conflict of interest}

The authors declare no conflict of interest.

\section{Acknowledgements}

We are grateful to all the people who helped with larval collections in particular to Silke Waap and Pedro Moreira. We also thank Administração do Porto de 
Aveiro who kindly provided access to the sample location and two anonymous referees for their suggestions on improving the paper. Fundação para a Ciência e a Tecnologia (FCT) supported a PhD grant to Carla Domingues (SFRH/BD/21593/2005). This work is part of the 'Connect- Connectivity of marine populations assessed with genetic and numerical modelling tools' research project, also funded by FCT (No. PTDC/BIABDE/65425/2006) under the European Regional Development Fund.

\section{References}

Aljanabi SM, Martinez I (1997). Universal and rapid saltextraction of high quality genomic DNA for PCR-based techniques. Nucleic Acids Res 25: 4692-4693.

Almeida MJ, Queiroga H (2003). Physical forcing of onshore transport of crab megalopae in the northern Portuguese upwelling system. Estuar Coast Shelf S 57: 1091-1102.

Belkhir K, Borsa P, Chikhi L, Raufaste N, Bonhomme F (1996-2004). GENETIX 405 Logiciel sous Windows TM pour la génétique des populations. Laboratoire Génome, Populations, Interactions, CNRS UMR 5171, Université de Montpellier II, Montpellier (France).

Belkhir K, Castric V, Bonhomme F (2002). Identix, a software to test for relatedness in a population using permutation methods. Mol Ecol Notes 2: 611-614.

Broekhuysen GL (1936). On development, growth and distribution of Carcinides maenas (L). Archs Neerl Zool 2: 255-399.

Calderón I, Palacín C, Turon X (2009). Microsatellite markers reveal shallow genetic differentiation between cohorts of the common sea urchin Paracentrotus lividus (Lamarck) in northwest Mediterranean. Mol Ecol 18: 3036-3049.

Carlton JT, Cohen AN (2003). Episodic global dispersal in shallow water marine organisms: the case history of the European shore crabs Carcinus maenas and C. aestuarii J Biogeogr 30: 1809-1820.

Christie MR, Johnson DW, Stallings CD, Hixon MA (2010). Selfrecruitment and sweepstakes reproduction amid extensive gene flow in a coral-reef fish. Mol Ecol 19: 1042-1057.

Domingues CP, Creer S, Taylor MI, Queiroga H, Carvalho GR (2010). Genetic structure of Carcinus maenas within its native range: larval dispersal and oceanographic variability. Mar Ecol Prog Ser 410: 111-123.

dos Santos A, Santos AMP, Conway DVP, Bartilotti C, Lourenço P, Queiroga H (2008). Diel vertical migration of decapod larvae in the Portuguese coastal upwelling ecosystem: implications for offshore transport. Mar Ecol Prog Ser 359: 171-183.

Excoffier L, Smouse PE, Quattro JM (1992). Analysis of molecular variance inferred from metric distances among DNA haplotypes: application to human mitochondrial DNA restriction data. Genetics 131: 479-491.

Flowers JM, Schroeter SC, Burton RS (2002). The recruitment sweepstakes has many winners: genetic evidence from the sea urchin. Strongylocentrotus purpuratus Evolution 56: 1445-1453.

Gilbert-Horvath EA, Larson RJ, Garza JC (2006). Temporal recruitment patterns and gene flow in kelp rockfish (Sebastes atrovirens). Mol Ecol 15: 3801-3815.

Goudet J (2001). FSTAT, a program to estimate and test gene diversities and fixation indices (version 2.9.3). [http://www. unil.ch/izea/softwares/fstat.html].

Hauser L, Carvalho GR (2008). Paradigm shifts in marine fisheries genetics: ugly hypotheses slain by beautiful facts. Fish Fish 9: 333-362.

Hedgecock D (1994). Does variance in reproductive sucess limit effective population sizes of marine organisms?. In: Beaumont A (ed). Genetics and evolution of aquatic organisms. Chapman and Hall, London, pp 122-134.
Hedgecock D, Barber PH, Edmands S (2007a). Genetics approaches to measure connectivity. Oceanography 20: 70-79.

Hedgecock D, Launey S, Pudovkin AI, Naciri Y, Lapègue S, Bonhomme F (2007b). Small effective number of parents $\left(\mathrm{N}_{\mathrm{b}}\right)$ inferred for a naturally spawned cohort of juvenile European flat oysters Ostrea edulis. Mar Biol 150: 1173-1182.

Hernbinger C, Doyle R, Taggart CT, Lochmann S, Brooker A, Wright JM et al. (1997). Family relationships and effective population size in a natural cohort of Atlantic cod Gadus morhua larvae. Can J Fish Aquat Sci 54: 11-18.

Hunt HL, Scheibling RE (1997). Role of early post-settlement mortality in recruitment of benthic marine invertebrates. Mar Ecol Prog Ser 155: 269-301.

Kordos LM, Burton RS (1993). Genetic differentiation of Texas Gulf Coast populations of the blue crab Callinectes sapidus. Mar Biol 117: 227-233.

Li G, Hedgecock D (1998). Genetic heterogeneity, detected by PCR SSCP, among samples of larval Pacific oysters (Crassostrea gigas) supports the hypothesis of large variance in reproductive success. Can J Fish Aquat Sci 55: 1025-1033.

Liu J-X, Ely B (2009). Sibship reconstruction demonstrates the extremely low effective population size of striped bass Morone saxatilis in the Santee-Cooper system, South Carolina, USA. Mol Ecol 18: 4112-4120.

Marta-Almeida M, Dubert J, Peliz A, Queiroga H (2006). Influence of vertical migration pattern on retention of crab larvae in a seasonal upwelling system. Mar Ecol Prog Ser 307: 1-19.

Moberg PE, Burton RS (2000). Genetic heterogeneity among adult and recruit red sea urchins, Strongylocentrotus franciscanus. Mar Biol 136: 773-784.

Moksnes PO, Pihl L, van Montfrans J (1998). Predation on postlarvae and juveniles of the shore crab Carcinus maenas: importance of shelter, size and cannibalism. Mar Ecol Prog Ser 166: $211-225$.

Nagaraj M (1993). Combined effects of temperature and salinity on the zoeal development of the green crab, Carcinus maenas (Linnaeus, 1758) (Decapoda: Portunidae). Sci Mar 57: 1-8.

Natunewicz CC, Epifanio CE (2001). Spatial and temporal scales of patches of crab larvae in coastal waters. Mar Ecol Prog Ser 212: 217-222.

Pascoal S, Creer S, Taylor MI, Queiroga H, Carvalho G, Mendo S (2009). Development and application of microsatellites in Carcinus maenas: genetic differentiation between Northern and Central Portuguese populations. Plos One 4: e7268.

Peakall R, Smouse PE (2006). GENALEX 6: genetic analysis in Excel. Population genetic software for teaching and research. Mol Ecol Notes 6: 288-295.

Peliz A, Marchesiello P, Dubert J, Marta-Almeida M, Roy C, Queiroga H (2007). A study of crab larvae dispersal on the Western Iberian Shelf: physical processes. J Marine Syst 68: 215-238.

Planes S, Lecaillon G, Lenfant P, Meekan M (2002). Genetic and demographic variation in new recruits of Naso unicornis. J Fish Biol 61: 1033-1049.

Planes S, Lenfant P (2002). Temporal change in the genetic structure between and within cohorts of a marine fish Diplodus sargus, induced by a large variance in individual reproductive success. Mol Ecol 11: 1515-1524.

Poulsen NA, Nielsen EE, Schierup MH, Loeschcke V, Grønkjær $P$ (2006). Long-term stability and effective population size in North Sea and Baltic Sea cod (Gadus morhua). Mol Ecol 15: 321-331.

Pujolar JM, Maes GE, Volckaert FAM (2006). Genetic patchiness among recruits in the European eel Anguilla anguilla. Mar Ecol Prog Ser 307: 209-217.

Queiroga H (1995). Processos de dispersão e recrutamento das larvas do caranguejo Carcinus maenas (L.) na Ria de Aveiro, $\mathrm{PhD}$ thesis, Universidade de Aveiro.

Queiroga H, Almeida MJ, Alpuim T, Flores AAV, Francisco S, González-Gordillo I et al. (2006). Tide and wind control of 
megalopal supply to estuarine crab populations on the Portuguese west coast. Mar Ecol Prog Ser 307: 21-36.

Queiroga H, Blanton J (2005). Interactions between behaviour and physical forcing in the control of horizontal transport of decapod crustacean larvae. Adv Mar Bio 47: 107-214.

Queiroga H, Costlow JD, Moreira MH (1994). Larval abundance patterns of Carcinus maenas (Decapoda, Brachyura) in Canal de Mira (Ria de Aveiro, Portugal). Mar Ecol-Prog Ser 111: 63-72.

Queller DC, Goodnight KF (1989). Estimating relatedness using genetic markers. Evolution 43: 258-275.

Relvas P, Barton ED, Dubert J, Oliveira PB, Peliz A, Silva JCB et al. (2007). Physical oceanography of the western Iberia ecosystem: Latest views and challenges. Prog Oceanogr 74: 149-173.

Rice AL, Ingle RW (1975). The larval development of Carcinus maenas (L.) and C. mediterraneus Czerniavsky (Crustacea, Brachyura, Portunidae) reared in the laboratory). Bull Br Mus Nat Hist (Zool.) 28: 103-119.

Rice WR (1989). Analysing tables of statistical tests. Evolution 43: 223-225.

Rose CG, Paynter KT, Hare MP (2006). Isolation by distance in the eastern oyster, Crassostrea virginica, in Chesapeake Bay. J Hered 97: 158-170.

Rousset F (2008). GENEPOP'007: a complete re-implementation of the GENEPOP software for Windows and Linux. Mol Ecol Resour 8: 103-106.

Rumrill SS (1990). Natural mortality of marine invertebrate larvae. Ophelia 32: 163-198.

Ruzzante DE, Taggart CT, Cook D (1996). Spatial and temporal variation in the genetic composition of a larval cod (Gadus morhua) aggregation: cohort contribution and genetic stability. Can J Fish Aquat Sci 53: 2695-2705.
Ryman N, Palm S (2006). POWSIM: a computer program for assessing statistical power when testing for genetic differentiation. Mol Ecol 6: 600-602.

Ryman N, Palm S, André C, Carvalho GR, Dahlgren TG, Jorde PE et al. (2006). Power for detecting genetic divergence: differences between statistical methods and marker loci. Mol Ecol 15: 2031-2045.

Selkoe KA, Gaines SD, Caselle JE, Warner RR (2006). Current shifts and kin aggregation explain genetic patchiness in fish recruits. Ecology 87: 3082-3094.

Selkoe KA, Henzler CM, Gaines SD (2008). Seascape genetics and the spatial ecology of marine populations. Fish Fish 9: 363-377.

Selkoe KA, Toonen RJ (2006). Microsatellites for ecologists: a practical guide to using and evaluating microsatellite markers. Ecol Lett 9: 615-629.

Siegel DA, Mitarai S, Costello CJ, Gaines SD, Kendall BE, Warner RR et al. (2008). The stochastic nature of larval connectivity among nearshore marine populations. P Natl Acad Sci USA 105: 8974-8979.

Tepolt CK, Bagley MJ, Geller JB, Blum MJ (2006). Characterization of microsatellite loci in the European green crab (Carcinus maenas). Mol Ecol Notes 6: 343-345.

van Oosterhout C, Hutchinson WF, Wills DPM, Shipley P (2004). MICRO-CHECKER: software for identifying and correcting genotyping errors in microsatellite data. Mol Ecol Notes 4: 535-538.

Veliz D, Duchesne P, Bourget E, Bernatchez L (2006). Genetic evidence for kin aggregation in the intertidal acorn barnacle (Semibalanus balanoides). Mol Ecol 15: 4193-4202.

Weir BS, Cockerham CC (1984). Estimating F-Statistics for the analysis of population structure. Evolution 38: 1358-1370.

Supplementary Information accompanies the paper on Heredity website (http://www.nature.com/hdy) 